\title{
Impact of demolition work of the environment, generated by mine closures in Jiu Valley
}

\author{
Vlad Lăutaru*, Marius Kovacs, Andrei Gireadă, and Alin Irimia \\ National Institute for Research and Development in Mine Safety and Protection to Explosion - \\ INSEMEX, 32-34 G-ral Vasile Milea Street, Petrosani, Romania
}

\begin{abstract}
Extractive industry has had and has negative effects on environmental factors. Limitation of industrial activities carried out in Jiu Valley, materialized by closure of mining units, brings to actuality the rehabilitation of areas occupied by constructions and surface utilities related to the technological process of underground coal extraction. First stage of surface rehabilitation and greening is the demolition of surface buildings by means of technical implosion / blasting or classic techniques. This stage generates a series of physicochemical pollutants that can have a significant impact on environmental factors. The main objective of the current paper is to identify pollutants and the negative effects they may have on human health as well as to reduce the environmental impact of materials from demolition operations. The paper has the advantage of quantifying waste resulting from demolitions in order to reduce impact on the environment by revalorizing the obtained materials (metal, concrete, wood, brick etc.) thus reducing the quantities of industrial waste to be stored. Thus, it is possible to plan the greening of areas affected by mining activities in the shortest possible time, correlated with the program of territorial systematization, in order to capitalize on new economic opportunities for use of these lands.
\end{abstract}

\section{Introduction}

Capitalization of natural resources is an anthropic activity that provides raw materials for many industrial branches. After depletion of mineral resources, the mining objectives go into closure process and, implicitly, the greening of affected area begins. The current paper deals with the environmental impact of these activities, focusing on greening phase of the mine closure project as part of the mining life cycle. Key aspects of technological and administrative building's greening are addressed and the necessary activities to bring the system to a balanced state within a reasonable time, are described. [1]

The subject of mining closure through the stage that aims at greening surface objectives is of particular importance to all the actors involved:

- for the mining companies in terms of reducing environmental, social and safety risks of the area, as well as in terms of provision of necessary funds to rehabilitate the area;

\footnotetext{
* Corresponding author: vlad.lautaru@insemex.ro
} 
- for authorities and the government, in terms of solving the acute environmental issues and social and economic revitalization of vast regions;

- for communities to avoid economic and social collapse.

Many of the surface objectives are decommissioned by blasting or imploding. Performing industrial building blasting activities for buildings to be decommissioned involves a series of operations that generate environmental pollution short-term risks but also risks for buildings and people in neighbourhoods. The waste resulting from demolition of surface structures within mining units is considerable and a series of steps and measures need to be established to streamline their reinsertion into the economic circuit [5].

\section{Closure of mining objectives}

Closure is an important step in the life cycle of a mining operation, being by far the most difficult aspect the mining industry has to face. Mining is only a temporary manner of land use, and the importance of the closure step is due to the need of returning degraded systems to a state of stability that will allow their future use. [1]

The decision to close a mining objective requires the analysis of a complex of factors that influence its efficiency, and can be of several ways as follows:

- Temporary total, when the activity ceases for a maximum period of 3 months, period when projects for revitalizing the activity are drawn up.

- Partial temporary, when the activity ceases for a maximum period of 3 months in some sectors of the exploitation.

- Conservation of exploitation, when the activity ceases for more than 3 months. This stage allows the subsequent revitalization of the activity based on a technical conservation project.

- The definitive partial closure, when the activity ceases in some sectors of the exploitation, with their decommissioning and the restoration of the environment.

- The total and definitive closure, when the activity ceases with the decommissioning of the exploitation and the restoration of the environment [2].

For this purpose, the mine closure plan must be an integrated part of the life cycle of a mining project and must be designed to ensure [2]:

- Long-term safety and health of population;

- Avoid physical and chemical deterioration of environmental resources;

- Long term effective and sustainable use of the site;

- Reduced adverse socio-economic impacts;

- Maximizing socio-economic benefits.

Thus, mining has to be performed according to the principles of sustainable development. Sustainable development is a set of integrated principles that involve environmental ecosystems, economic growth, social equity, policy integration and the idea that effective solutions can only be achieved through an interdisciplinary approach to problems. This also implies taking into account the future repercussions of present decisions - which are not all favourable. In the case of mine closure, sustainable development offers opportunities and challenges, but most importantly it must provide viable solutions [2].

\section{Demolition of surface objectives through blasting and its environmental impact}


After the mine closure, technological and administrative buildings, except for those kept for other destinations, are demolished. Mine closure technical projects stipulates for buildings planned to be demolished.

The demolition works of the constructions are executed by demolishing the superstructure, the elevation of the constructions and removing the foundations of the constructions and technological equipment. Another way is to refill the gaps resulting from removing foundations with appropriate materials and compacting them to the ground level. Demolition can also be performed by clearing the site of debris, debris and removing hazardous materials from the yard. The latter method is continued by leveling the ground in order to facilitate the restoration of the environment and playback in the initial circuit of the land. As a result of the demolition works of the buildings, as many reusable and reusable materials and elements will be recovered, so that their qualities are preserved.

Demolition activities are covered by the EC Directive on safety and health requirements for mobile construction sites (Directive 92/57 / EEC). This Directive provides for measures to be taken to protect health, safety and well-being when a building site is established in the area.

Blast demolition of surface objects within the studied mining units constitutes an important risk factor for the health of inhabitants in the area, respectively for civil constructions in the immediate vicinity, through the concentration of particulate matter resulting from blasting of concrete, brick and wood structures.

The use of explosive energy for the controlled demolition of buildings involves the knowledge in several areas, such as: explosion physics, materials behaviour at shock waves, structure dynamics and seismic engineering.

When designing a blast, it is very important to take into account, even roughly, the degree of danger that may occur because of vibrations. This is essential when using the explosive demolition method in the vicinity of weak structures. Under these circumstances, it is mandatory to estimate the maximum value of the vibration source parameter (the mass of the structure hitting the ground, and sometimes the amount of explosive used to destroy the underground pillars, initiated on a stage in the case of demolitions) causing strain without subjecting the structures to strains beyond their safety limits.

When assessing the explosion-induced seismic effect, it is very important to assess the possible damage that may occur depending on the type of construction and its condition and their correlation with the dynamic parameters of oscillations generated by the explosive demolition.

Monitoring seismic effects with devices placed in the proximity of protected sites will confirm whether the assessment has been performed correctly and if seismicity level falls in the non-hazardous range.

Since exposure to seismic waves and the degree of structural supportability are determined by vibrational phenomena, there's the possibility of producing (quasi) resonance when the terrain dominant frequencies and construction ones have close values. This phenomenon is a dangerous amplification of the scale or parts response of the structure, causing serious damage to the construction even at low vibration levels. [3]

The amount of breathable dusts resulting from demolition works may have adverse effects on the health of residents in the area, such as respiratory problems. If structures of surface objects have asbestos in their composition, the risk factor on the health of inhabitants in the area increases considerably, taking into account the carcinogenic effect of asbestos. In this case, demolition works should be carried out and monitored by authorized companies, which, according to European Directive 83/477/EEC, as amended by Directive 2003/18/EC, must, prior to carrying out demolition or asbestos demolition works, provide proofs on their capabilities in this area. Such proofs shall be established in accordance with national laws and/or practices. Asbestos-containing waste management operations will be 
performed in accordance with REACH (European Community Regulation on Chemicals and their Safe Use). [4]

In conclusion, demolition of mining objectives generates dust, gas, noise, vibration and possibly asbestos dust. In this respect, both the population in the area (i.e. households that are approximately $1000 \mathrm{~m}$ away) and the environment can be affected by these noxae. In order to prevent pollution, a series of technical and organizational measures must be taken, such as: wetting the area to prevent dust release, placing movable sound absorbing panels to reduce the high noise produced by blasting activities, demolition after checking the weather forecast, times when air currents velocity is high being recommended, thus gasses generated by the blast will disperse more rapidly resulting in a higher dilution of the noxious concentrations.

\subsection{Quantification of waste resulting from demolition activities}

In order to minimize the environmental impact generated by demolition activities of technological and administrative mining constructions, it is necessary to quantify the resulting waste. The main categories of waste that may result from decommissioning and demolition of mining constructions are: reinforced concrete, brick and precast BCA, recoverable scrap, wood, electric conductors, oil resulting from decommissioning of transformer stations, lubricants, household waste, tires and plastic masses.

For the quickest and most efficient quantification of waste resulting from demolitions, a quantitative estimate of materials used in surface construction can be made using construction projects, to assess both the manner and approximate amount of waste to be reintroduced in the economic circuit, as well as the location and surface of land needed to store waste that cannot be recovered.

Much of the amount of concrete resulting from demolition of surface objectives can be used as a backfill to fill the voids remaining in the underground of other mining units, or can be redeemed to certain commercial agents carrying out construction activities where there is a need for backfilling, such as raising land to the level required for the construction of a rail or road, dyke constructions, etc.

The old recovered iron will be $100 \%$ recycled to steelworks, as well as wood that can be sold to commercial woodworking agents for use in various technological processes such as furniture manufacturing and pellet production.

Brickworks and whole BCA prefabricates can be reused in industrial construction as well as in civil engineering if they have not been chemically contaminated, the rest of the brick waste and degraded BCA prefabricates are to be stored in suitable warehouses.

Metal can also be recovered from the resulting electric conductors, and the plastics can be recycled for re-use.

\section{Greening the surface objectives of Lonea and Lupeni mining units}

. It is mandatory for the local communities to rehabilitate the sites affected by the mining industry. The rehabilitation plan, which is a consistent part of the project to transform the mine into a functional site, is focused ont he land and its purpose. This objective must be reached after a public consultation, involving all the intrested parties, such as the local administration, local NGO's and the residents. 
From the start the technical-mining measures must be oriented towards refurbishment, in order to achieve high efficiency and quality greening of surfaces and in order to have the conditions for the economic re-circuit of affected areas, according to set objectives.

The area studied in the paper is the perimeter of Petrila Mining Unit (fig.1), located on the administrative territory of Petrila.

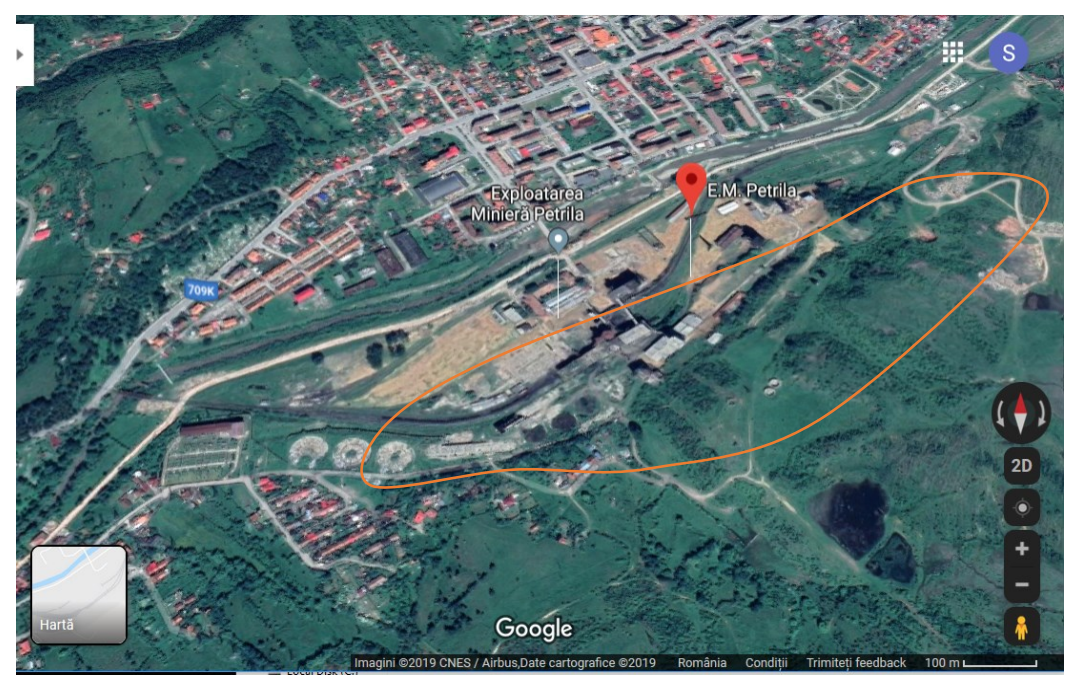

Fig. 1 Petrila mine perimeter

Cartographic data obtained with Airbus, shows that the perimeter of Petrila Mine having surface mining sites is of approximately $170,000 \mathrm{~m}^{2}$, with technological and administrative buildings occupying approximately $31,000 \mathrm{~m}^{2}$.

Part of the surface buildings belonging to Petrila Mine were demolished in 2017 when the National Mine Closing Company was authorized to demolish 25 buildings belonging to the mine. Eventually, it only demolished 4 of the 25 buildings, while the remaining entered a conservation program. The waste resulted as a result of the demolition process were used to embank the mining pits, which at that time were half filled with rabble, while the scrap iron was salvaged and sold.

After the demolition, the vacant land entered a process of redevelopment, which includes the following stages:

- recovery and preservation of vegetal soil;

- landscaping;

- levelling surfaces;

- depositing vegetal soil on levelled surfaces;

- land improvement.

Recovery and preservation of vegetal soil is a compulsory activity for mining units, having a special importance, starting with the establishment of soil layer thickness, excavation, transport, storage and preservation. To perform this activity, it is necessary to verify by trial the soil in the perimeter of the future rehabilitated area. Establishing the thickness of the vegetal soil is done by performing manual drillings, ditches, pits located at $100 \mathrm{~m}$ intervals, the results being then marked on topographic maps and on sections drawn on these drillings. From the beginning, a pedologic and agrochemical mapping of affected areas must be performed as well as mapping of geological stratums in the roof of the reservoir, in order to find their fertility potential and to make recommendations on decaying technology, landfilling and surface storage.[5] 
Up to now, according to studies carried out, several methods of recovering degraded land, as a result of demolition activities of surface mining, can be used. These methods are chosen based on their distance from the local community, its requirements and technical possibilities. Recovery can be: naturalistic recovery, recreational recovery, productive recovery, residential recovery, cultural recovery.

A concrete example of cultural rehabilitation and surface buildings conservation is Petrila Mine, where part of the surface buildings, which survived the demolition process, were declared historical heritage landmarks. Presently, Hunedoara County Council has initiated a process to purchase the mine, which will integrated into the Dacian-Roman Civilization Museum from Deva . Also, ont the premises of Petrila Mine there are is a museum (The Museum of The Mine Rescuer - fig. 2) and a public library.

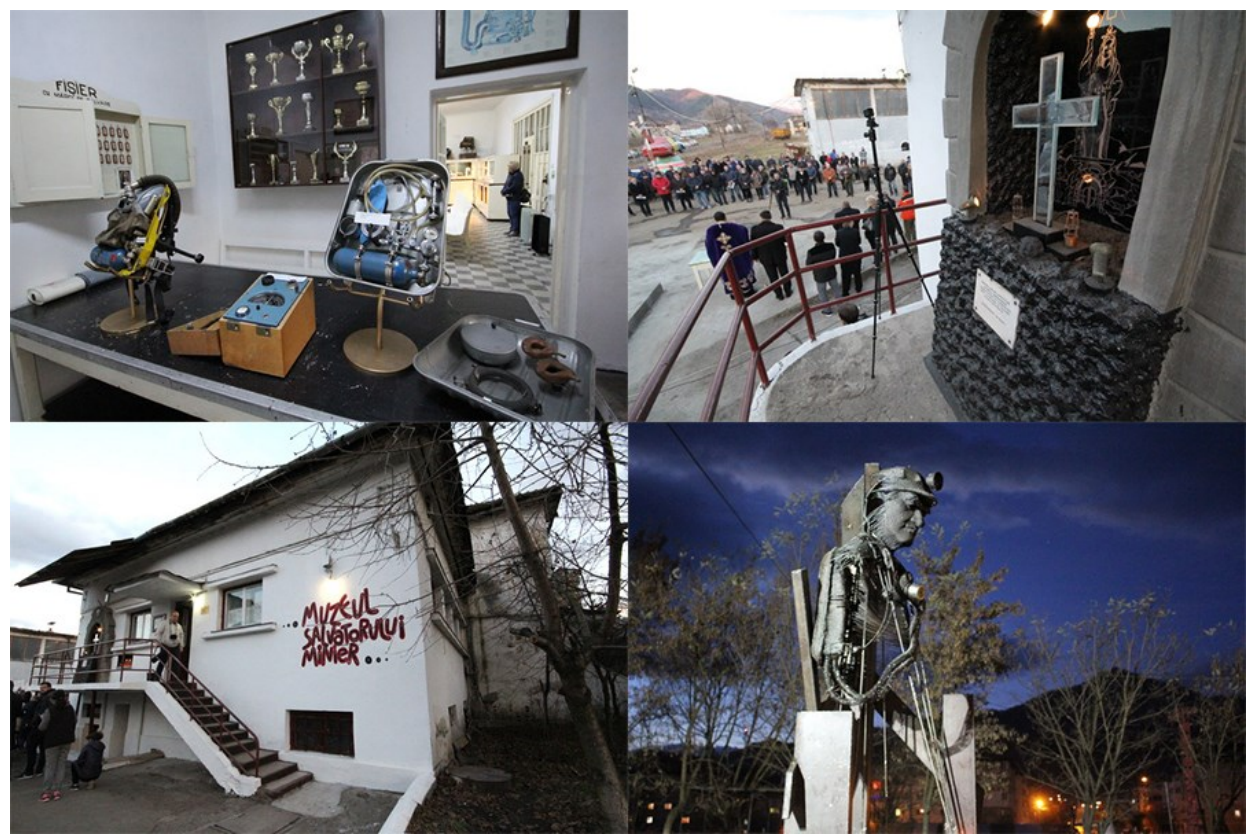

Fig. 2 Mine rescuer's Museum

\section{Conclusions}

The effects generated by mining constructions demolition activities have a negative impact both on the environment by polluting with waste and gases resulted from blasting, the effects of seismic waves generated by blasting, as well as for the health of inhabitants near the mining units through effects generated by dusts in suspension, asbestos fibres and gases resulting from blasting. To reduce the effects on the environment, it is necessary to quantify the waste resulting from demolition activities following a quantitative analysis, to be reused or stored accordingly.

- Following an analysis of opportunities created, the mining constructions can be transformed into museums, thus avoiding the negative effects on the environment produced by demolition activities.

- To establish an optimal method of recovering the degraded land after demolition of surface mining objectives, a complex interdisciplinary analysis has to be performed and 
depending on the results, after the analysis is completed, the optimal method of area rehabilitation, in the shortest time, can be chosen.

\section{References}

1. D. Fodor, Mining and environment, Editura Corvin, Deva, 2015

2. E.R. Medves, N. Turdeanu, Closing and ecological reconstruction of the mining objectives, dynamic processes in continuous adaptation to the concrete conditions of the land and to the request of the local communities, in a viable economic context, The Mines Magazine nr.3/2008

3. A. Kovacs, C. Lupu, E. Ghicioi, C. Ciocoiu, G. Vasilescu, E. Gheorghiosu, D. Rus, S. Ilici, C. Cioara, C, Jitea, National guide for risk assessment related to the demolition activity of some industrial and civic buildings with the help of explosives, Publishing House INSEMEX, 2014

4. A.N. Călămar, G.A. Găman, D. Pupăzan, L. Toth, I. Kovacs, Analysis of enviromental components by monitoring gas concentrations in the environment, Enviromental Engineering and Management Journal EMMJ, Vol.16, nr.6, 2017

5. M. Lazar, Rehabilitation of degraded lands, Publishing House Universitas, Petroșani, 2019 